\title{
Experimental and Numerical Bending Analysis of Steel/Resin-Talk Sandwich Material
}

\author{
Pratama Yuli Arianto ${ }^{1}$, Achmad Zubaydi ${ }^{1}$, Bambang Piscesa $^{2}$, and Tuswan ${ }^{1}$
}

\begin{abstract}
Sandwich material can be used as the substitute for the ship conventional material. The core sandwich material used in this study consisted of a talk-resin-catalyst. The core mixture proportion is $90 \%$ resin and $10 \%$ talk. A thick steel plates is used as the face of the core sandwich material. Both experimental and numerical simulations are carried out to investigate the bending or flexural behavior of the proposed sandwich material. Three-point bending test has been carried out to determine the yield stress and maximum stress as well as the damage mechanism of the specimen up-to failure. From the investigation, the first failure process occurred at the mid-span as flexural cracks. As the load continue, these flexural cracks progressed until fully fracture of the core material take places. From the experimental investigation, it was found that the yield stress and maximum stress of the sandwich panel are 22.88 MPa and 28.63 MPa. On the other hand, numerical simulation is carried out using ABAQUS which has shown to be sufficient to predict the response of the sandwich-panel. However, a more sophisticated constitutive model is required to successfully model the experimental behavior in close agreement.
\end{abstract}

\section{Keywords-Bending Test, Sandwich Structure, Failure Mechanism, Talk, Unsaturated Polyester Resin.}

\section{INTRODUCTION}

$\mathrm{S}_{\mathrm{s}, \mathrm{a}}^{\mathrm{a}}$ andwich structure is one of the alternative construction types that has been widely used in marine, land and aerospace fields. Sandwich material is lightweight but strong enough and less costly compared to conventional material [1][2][3][4], and [5]. By using this sandwich material, the weight of the structure can be reduced up to $10 \%$ compared to the conventional ones [6]. Furthermore, this sandwich material is easy to fabricate and have more benefits [7].

Research to find the optimum configuration of the sandwich material have been carried out by researchers. Various material composition for the face and core of sandwich structure like fiber, steel, aluminum, resin and others for face material, and resin, talk, fiber, foam, plastic foam, polyurethane [8] and others as a core material have been investigated. Moreover, reuse material was also utilized as the filler core of the material, for instance, clamshell, eggshell, rice husk, and sawdust. The shape of a core was also already studied with the various shape like $\mathrm{V}, \mathrm{I}, \mathrm{Vf}, \mathrm{C}, \mathrm{Z}$, hat-profile, key, tube, square-tube, and X [9].

The authors' research group have studied the sandwich material made of steel as the face and resin as the core shown that the core material has a brittle behavior. To decrease the brittleness index of the core, additional filler material is used [10][11]. Abdullah studied the use of clamshell powder filler for the core material with $10 \%-$ $50 \%$ of the total weight used in the mixture [12]. The optimum composition was found to be $30 \%$ of the total weight with the maximum tensile strength and the modulus of the core are $37.2 \mathrm{MPa}$ and $331 \mathrm{MPa}$, respectively. Mula studied the Eggshell powder filler for the core material with $30 \%$ composition of the total weight and resulted in the maximum tensile strength and modulus are 28.13 MPa and $300 \mathrm{MPa}$, respectively [13].

Resin filler by using rice husk [14] showed that the

Pratama Yuli Arianto, Achmad Zubaydi, and Tuswan are with Department of Naval Architecture, Institut Teknologi Sepuluh Nopember, Surabaya, 60111, Indonesia. E-mail: pratamayarianto@gmail.com.

Bambang Piscesa is with Department of Civil Engineering, Institu Teknologi Sepuluh Nopember, Surabaya, 60111, Indonesia. maximum tensile strength and modulus elasticity is in 5\% ratio of total core weight by 55.215 $\mathrm{MPa}$ and $392.5 \mathrm{MPa}$ [14]. Wood sawdust as a filler of the core in sandwich material showed the usage can be decreased from $5 \%$ to $20 \%$ ratio total weight of the core material which has a maximum tensile strength (with 5\% mixture composition) by $39.14 \mathrm{MPa}$ and maximum modulus elasticity (with 10 $\%$ mixture composition) by $164.23 \mathrm{MPa}$ [15]. In this paper, the combination of $90 \%$ resin, $10 \%$ talk and $0.3 \%$ catalyst are used as the core material while the faces material is designed to be using the steel material.

\section{METHOD}

The step of this research is divided into two methods. There is an experimental and numerical methods. In the experimental method, the experiment processes based on ASTM C 393 - 00 for Standard Test Method for Flexural Properties of Sandwich Constructions [16]. For the numerical method, ABAQUS software is used to run the finite element simulation for the sandwich panel specimen.

In this research, accommodation working barge for the object which converts to be sandwich material. The midship section of the ship can be seen in Figure 1. For calculating the dimension of the sandwich material, the minimum thickness is based on Lloyd's Register: Provisional Rules for The Application of Sandwich Panel Construction to Ship Structure. Table 1 explains that the minimum thickness depends on the type of applied sandwich condition. The thickness of the core is not to be less than $15 \mathrm{~mm}$ [17].

The thickness allowance for each construction position of the ship is presented in Table 2. Moreover, the minimum thickness can be calculated with Equation 1 [17].

$$
R=0,01 A_{R} 0,1\left[\frac{b^{2}}{d\left(t_{1}+t_{2}\right)}+11,7\left(\frac{b t_{c}}{d^{2}}\right)^{1,3}\right]+k P_{e q, R} ; \leq
$$

$$
\begin{aligned}
& A_{R}=\left(\frac{a}{b}\right)^{0,56} \\
& P_{\text {eq, } R}=\frac{z_{\text {rule }}}{l^{2}}, \text { in } \mathrm{N} / \mathrm{mm}^{2} \\
& l=\text { length of the panel, in meters }
\end{aligned}
$$




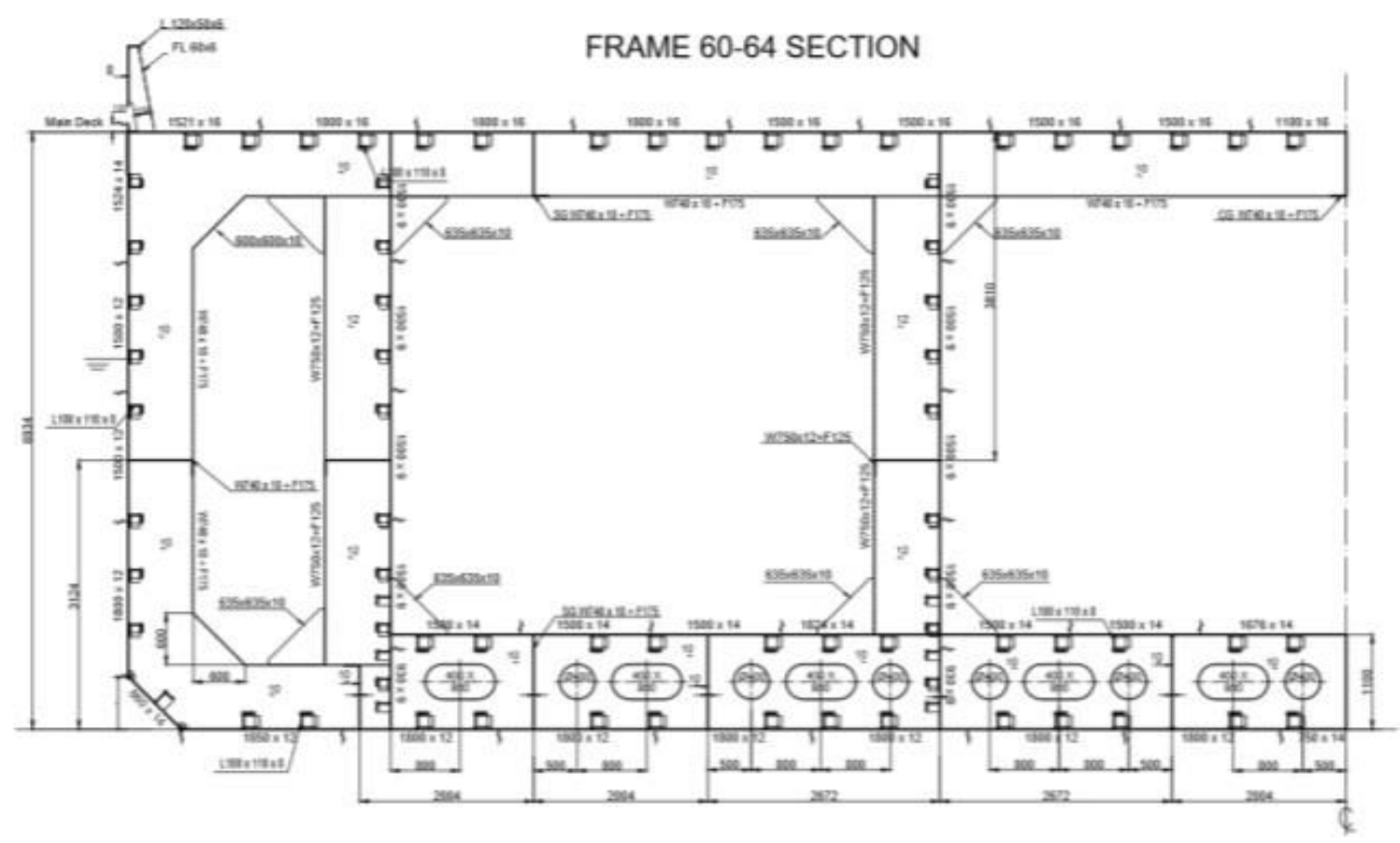

Figure 1. Midship section of Accommodation Working Barge.

TABLE 1.

MINIMUM THICKNESS OF THE SANDWICH PANEI

\begin{tabular}{ccc}
\hline \multirow{2}{*}{ Item } & \multicolumn{2}{c}{ Minimum thickness in $\mathbf{~ m m}$} \\
\cline { 2 - 3 } & New Construction & Overlay Construction \\
\hline $\mathrm{t} 1_{\text {MIN }}$ & 3,0 & 3,0 \\
$\mathrm{t} 2_{\mathrm{MIN}}$ & 3,0 & $50 \%$ of the as-built \\
\hline \hline
\end{tabular}

TABLE 2.

THICKNESS ALLOWANCE

\begin{tabular}{lccc}
\hline \hline Structure & $\mathbf{t a}_{\mathbf{R}}$ & $\mathbf{t a}_{\mathbf{1}}$ & $\mathbf{t a}_{\mathbf{2}}$ \\
\hline Bottom shell & 1 & 0 & 1 \\
Side shell & 1 & 0 & 1 \\
Inner bottom, hopper plating & 2 & 1 & 1 \\
Inner bottom, at the crown of tank & 3.5 & 1 & 2.5 \\
Strength deck & 2.5 & 2.5 & 0 \\
Internal deck & 0 & 0.0 & 0 \\
Superstructure Deck & 0 & 0.0 & 0 \\
Watertight bulkheads & 0 & 0.0 & 0 \\
Deep tank bulkheads & 2.5 & 0.0 & 2.5 \\
Deep tank crown which is also a & 3.5 & 1.0 & 2.5 \\
deck & & & \\
Vehicle deck clear of & 2 & 2 & 0 \\
tanks & & &
\end{tabular}

$\mathrm{Z}_{\text {rule }}=$ equivalent section modules, in $\mathrm{cm}^{3}$

$t_{c}=$ selected core thickness, in $\mathrm{mm}$

$a=$ length of the panel at longest edge, in $\mathrm{mm}$

$\mathrm{b}=$ breadth of the panel at the shortest edge, in $\mathrm{mm}$

$\mathrm{d}=$ thickness parameter, in $\mathrm{mm}$

$t_{1}, t_{2}=$ thickness of the top bottom plating, in $\mathrm{mm}$

$\mathrm{k}=$ steel strength factor

\section{A. Material}

The composite sandwich structure is created by the casting process. The process divided into four stage processes. These processes are the preparation of face material, creating a core, casting and molding process, and reactivity control. The dimension and material properties of the sandwich panel presented in Figure 2, Table 3, and Table 4.

The first process is to release the rust on the steel by grindstone. The aim of this process is to strengthen the adhesive from the face to the core. The second process is
TABLE 3.

THE DIMENSION OF SANDWICH MATERIAL

\begin{tabular}{lrcc}
\hline \hline Part & Length & Breadth & Thickness \\
\hline Unit & $\mathrm{mm}$ & $\mathrm{mm}$ & $\mathrm{mm}$ \\
Face & 170 & 60 & 6 \\
Core & 170 & 60 & 15 \\
\hline \hline
\end{tabular}

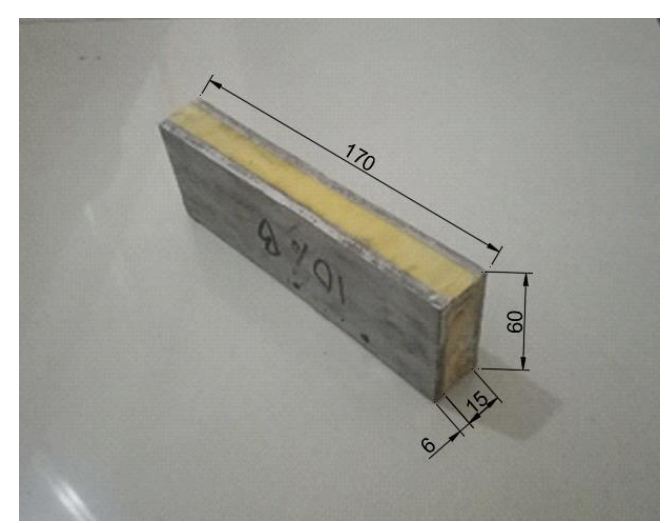

Figure 2. Sandwich structure.

to create the core by specific composition, which consisted of $90 \%$ unsaturated polyester resin, $10 \%$ talk powder and $0.3 \%$ catalyst. All of the core material is mixed using a mixer. In Figure $3 a$ to Figure $3 d$, there is a plastic glass that contains catalyst, resin, talk powder, and moisture of all with adding yellow dye respectively.

In the third process, the mold is made using cardboard with a specified size (as shown in Table 3) according to the requirements of ASTM C 393 - 00 for Standard Test Method for Flexural Properties of Sandwich Constructions [16]. Gluing process from the cardboard to the steel by using electric glue can be seen in Figure $4 \mathrm{a}$ and $b$. The mixture is poured into the mold when the mold has been created where present in Figure 4c.

The last stage consisted of the compaction process of the mixture liquid up-to 24 hours. The process from liquid to solid requires a significant amount of time and the specimen must through to several temperatures setting from low to high temperature, and returns to low 


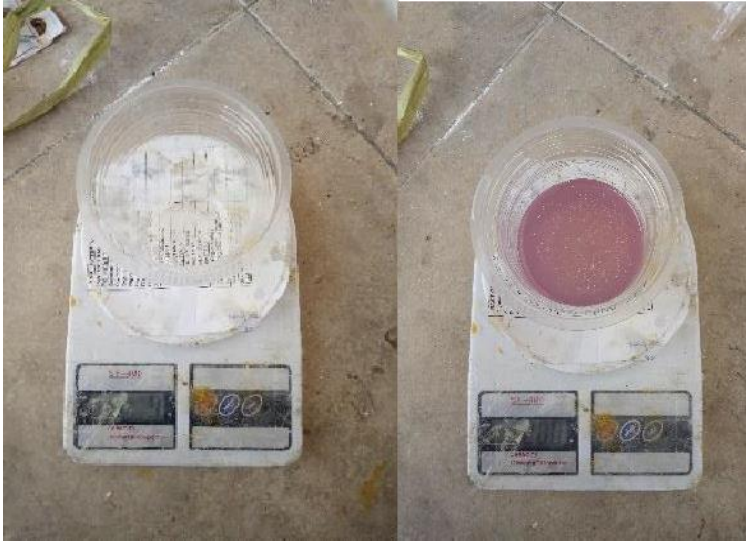

(a)

(b)

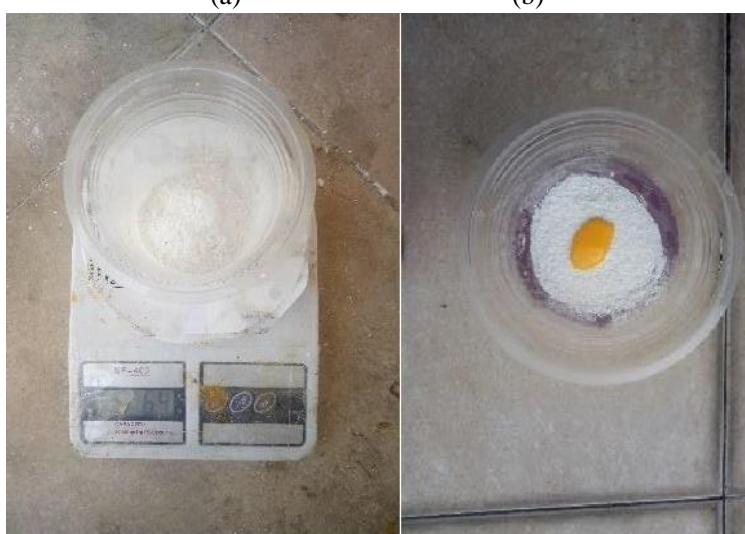

(c)

(d)

Figure 3. Composition of core material.

temperatures once finished, this is the reaction of catalyst, resin and talk powder to be a solid part and stick to the face of sandwich panel. The process of removing the cardboard from the mold is executed when the core is completely dry and dense.

\section{B. Experimental Method}

In this research, the apparatus for bending test is based on ASTM C $393-00$ which is for Standard Test Method for Flexural Properties of Sandwich Constructions in three-point bending test, and it has been fulfilled to support this studies. A 50 tonnes capacity servo-controlled Universal Testing Machine (UTM) is utilized for this research with a constant strain rate of $1 \mathrm{~mm} / \mathrm{min}$. Dial gage and high-precision data logger is used in this study [16]. Based on ASTM C393 - 00, the dimension of this experiment can be computed and is shown in Table 3 .

The output of this test is about failure mode and loaddisplacement curve, and it can be analyzed the trend of the curve, and every single movement of it. The yield and maximum force also can be calculated with Equation 2 and 3.

$$
\begin{aligned}
& F_{t}^{\text {yield }}=\frac{P_{\text {yield }}}{(d+c) b} \\
& F_{S}^{\text {ult }}=\frac{P_{u l t}}{(d+c) b} \\
& F_{t}^{\text {yield }}=\text { core shear yield strength, } \mathrm{MPa} \\
& F_{S}^{\text {ult }}=\text { core shear ultimate strength, } \mathrm{MPa} \\
& P_{\text {yield }}=\text { force at } 2 \% \text { offset shear strain, } \mathrm{N} \\
& P_{\text {max }}=\text { maximum force prior to failure, } \mathrm{N} \\
& t=\text { nominal facing thickness, mm } \\
& d=\text { sandwich thickness, mm } \\
& c=\text { core thickness, mm } \\
& b=\text { sandwich width, mm }
\end{aligned}
$$

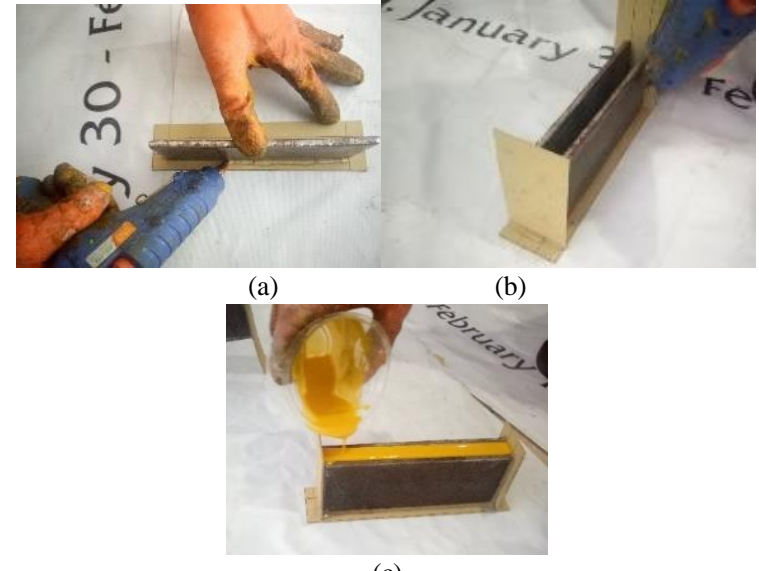

(c)

Figure 4. Molding and pouring process.

TABLE 4.

MATERIAL PROPERTIES OF CORE AND FACE IN SANDWICH PANEL

\begin{tabular}{lccc}
\hline \multicolumn{1}{c}{ Part } & Unit & Face [10] & Core [18] \\
\hline Tensile & $\mathrm{MPa}$ & 447.28 & 22.83 \\
Strength & & & \\
Yield Strength & $\mathrm{MPa}$ & 292.74 & \\
$\begin{array}{l}\text { Flexural } \\
\text { Strength }\end{array}$ & $\mathrm{MPa}$ & 482.27 & \\
$\begin{array}{l}\text { Shear Stress } \\
\text { Modulus }\end{array}$ & $\mathrm{MPa}$ & 110.23 & \\
Elasticity & $\mathrm{MPa}$ & $199,877.63$ & 254.65 \\
Shear Modulus & $\mathrm{MPa}$ & $60,573.26$ & 110.86 \\
Poisson Ratio & & 0.3 & 0.149 \\
Max Deflection & $\mathrm{mm}$ & 3.82 & \\
\hline \hline
\end{tabular}

\section{Numerical Bending Analysis}

In this section, numerical linear simulations are carried out using the finite element software ABAQUS to capture the flexural behavior of the sandwich panel specimen. Eight-node solid linear brick element (C3D8) is used to model the core material, a 4-node doubly curved general purpose shell element (S4) is selected to model the steel plates. The dimension and material properties of the sandwich is shown in Table 3 and Table 4 . In order to model contact interaction between the faceplate and core material, a surface to surface contact element with finite sliding formulation is used. In modeling the contact property, the tangential behavior is modeled by penalty friction formulation with the friction coefficient of 0.9 , and the normal behavior is using the hard contact model and separation after contact is allowed. Pinned boundary condition is used to model the support and displacement control at the mid-span node is used. Isotropic material properties are set for both the steel and the core material. The core is set to behave always elastic while the steel material follows the $J_{2}$ plasticity model.

A mesh convergence analysis is crucial and should be treated well. In order to obtain a reliable results, a mesh convergence study was carried out. Figure 9 shows the mesh convergence analysis. The parameter to be checked is the reaction force. As shown in Figure 9, as the meshsize become smaller, the value of the reaction force asymptote to a constant value. Based on Figure 9, the mesh size used in this study is limited to 0.0015 which gives the total number of elements 54,320.

\section{RESULT AND DISCUSSION}

\section{A. Failure Process}

Figure 10, Figure 11, Figure 12 and Figure 13 show the failure process of the sandwich material. The first failure 


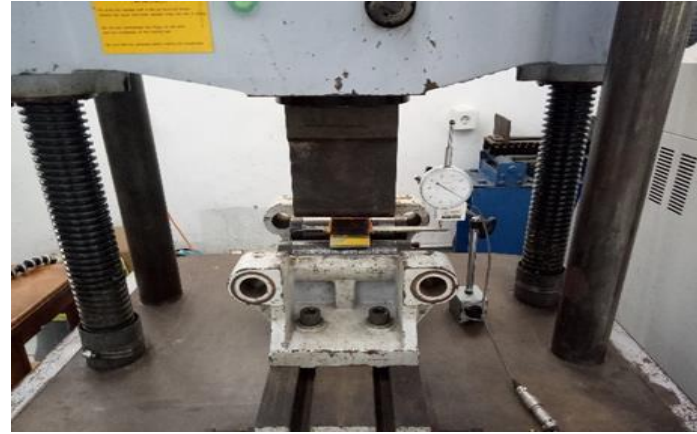

Figure 5. The layout of dial gauge.

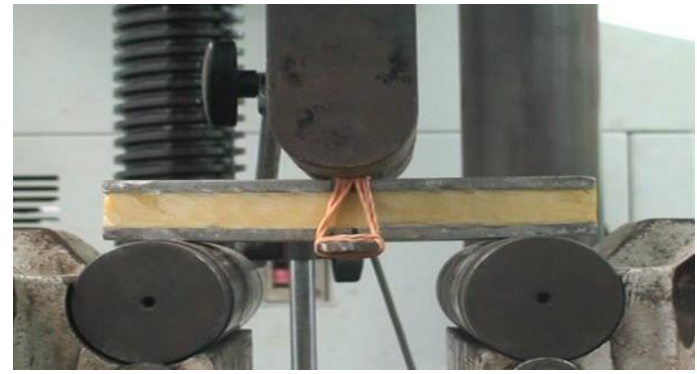

Figure 6. The position of bending test.

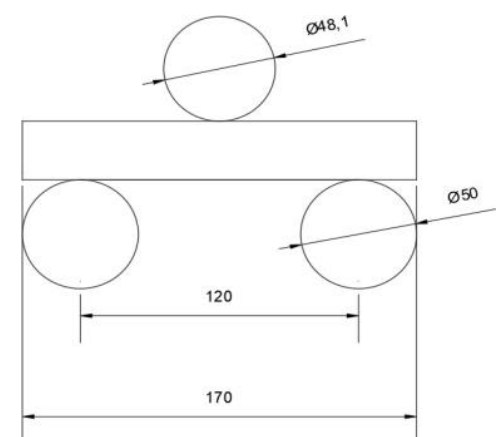

Figure 7. The layout of the experiment (mm).

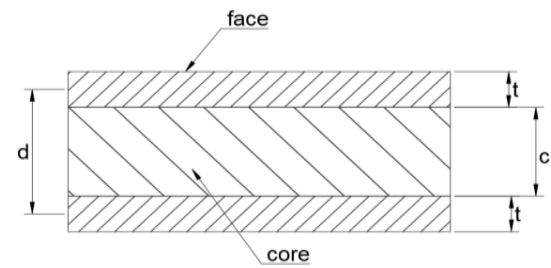

Figure 8. Sandwich Panel.

happens when the flexural cracks in the midspan of the sandwich material occurred. These flexural cracks propagate and delamination between the core and faces take places. When the first crack occurs, it implies there was delamination between the core and the faces of the sandwich panel. If the resin strength is higher than the bond strength between the face and core, the crack will appear in another part of the core and vice versa. As the load continue, the crack propagates and delamination between the core and the faces become more pronounce. The load-deflection curve suddenly drops after the core material is completely fractured.

\section{B. Typical Load-Displacement Curves}

Figure 14 shows the overall load-displacement curves while Figure 15 shows the load-displacement curves for a range of displacement from 6 to $12 \mathrm{~mm}$. In Figure 14 the pattern of every experiment from the first experiment until the third experiment is similar. The first yield indicates the first flexural crack in the core of sandwich material. And

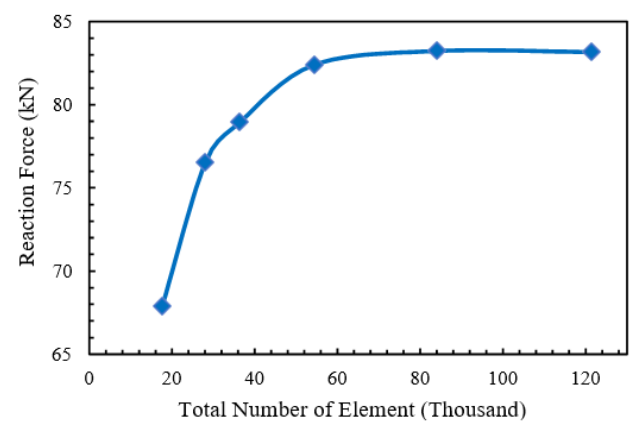

Figure 9. Mesh convergence analysis.

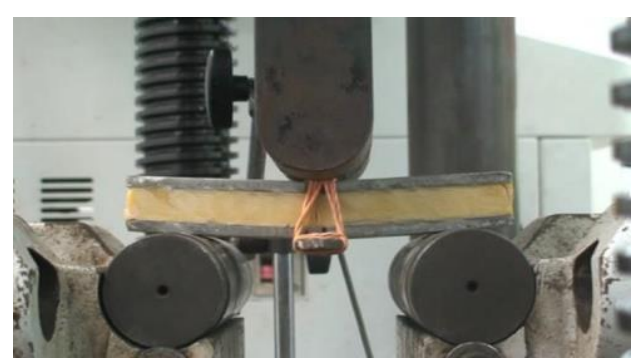

Figure 10. The first failure of the bending process.

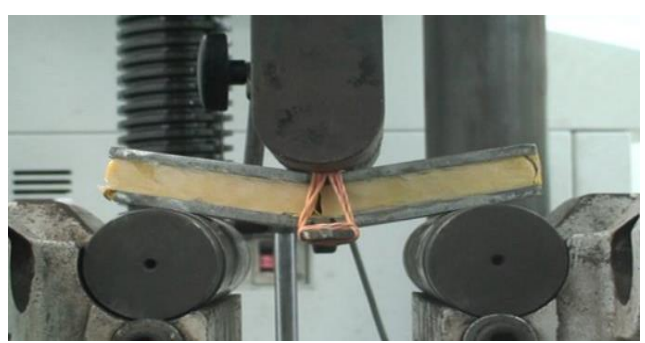

Figure 11. The first delamination of core and face.

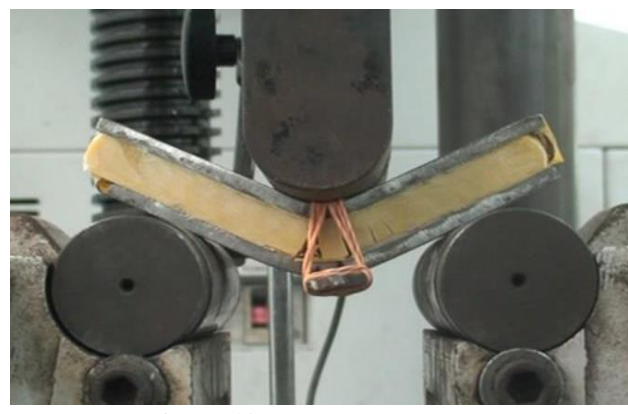

Figure 12. Crack in other parts.

the straight line from the first crack $(3 \sim 4 \mathrm{~mm})$ to the second crack shows $(17 \sim 20 \mathrm{~mm})$ the bond strength of the sandwich panel material. From Figure 15, the loaddisplacement curve between the ranges of 6 to $12 \mathrm{~mm}$ shows the similar behavior. Hence, variation in the first crack was due to variation in material during casting.

With the dimension of specimens and calculation by using sectional analysis, $\mathrm{P}_{\text {yield }}$ of the sandwich panel is in $57,660 \mathrm{~N}$ dan $\mathrm{P}_{\max }$ in 72,150 N. With the equation 2 and 3 , the yield stress (Fsyield) and maximum stress $\left(\mathrm{Fs}_{\mathrm{ult}}\right)$ are 22.88 MPa and 28.63 MPa.

\section{Numerical Result}

In this section, the result from the finite element simulation is presented. The load-displacement curve shown an almost straight line due to the inability of the used constitutive model to simulate the delamination between the steel and the core faces, as well as the flexural cracks in the core material. A fracture related constitutive model should be used in the future simulations. By 


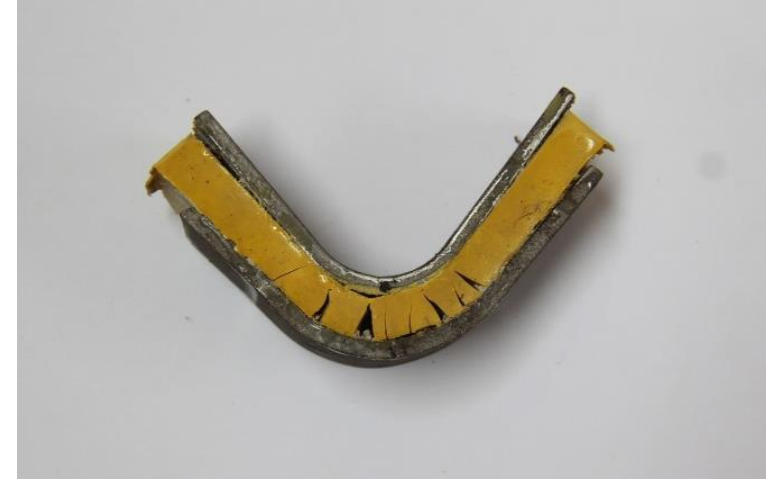

Figure 13. The last deformation of bending test.

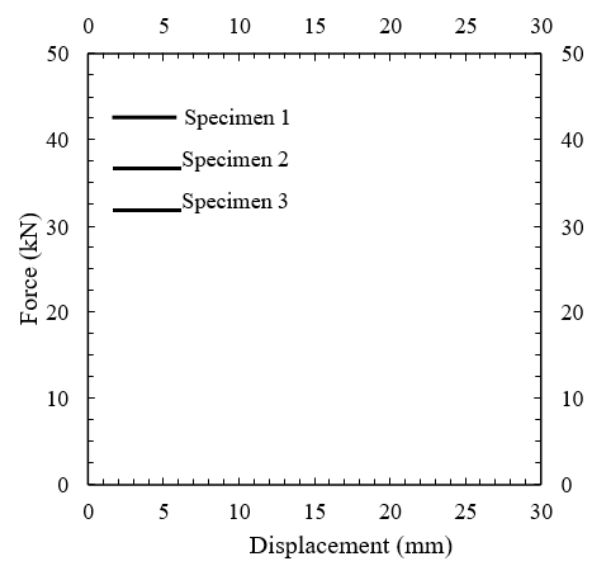

Figure 14. Load-displacement curve in 0 - $25 \mathrm{~mm}$.

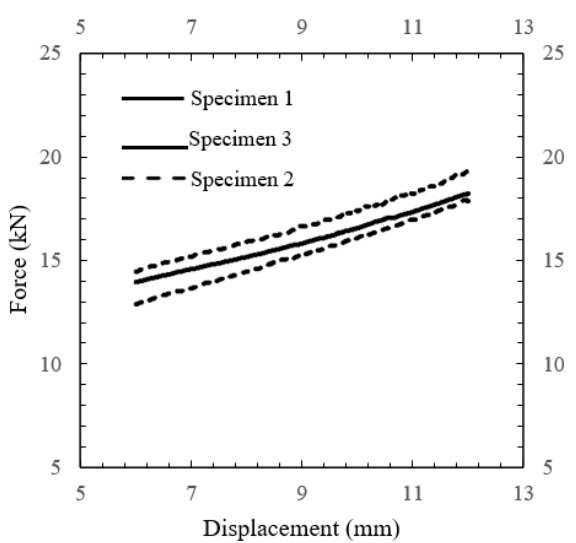

Figure 15. The load-displacement curve in 6 to $12 \mathrm{~mm}$.

comparing the maximum load in the elastic region between using the sectional analysis and the numerical analysis was in good agreement. By using sectional analysis, the maximum load $\left(\mathrm{P}_{\max }\right)$ was found to be 72,150 $\mathrm{N}$ and the corresponding displacement was $0.0305 \mathrm{~m}$. By using the numerical analysis, the maximum load obtained with the same displacement value $(0.0305 \mathrm{~m})$ was 82,388 $\mathrm{N}$. Figure 16 shows the load-displacement curve between the experimental and numerical investigation. Figure 17 shows the reaction force contour at the maximum load. As shown in Figure 17, the stress-concentration occurred at the support and loading boundaries condition.

\section{CONCLUSION}

This paper present both numerical and experimental investigation on the flexural behavior of the sandwich panel made of steel and resin (talk) as the core material. Both the failure processes and the load-displacement curve of the specimen were examined. The failure process

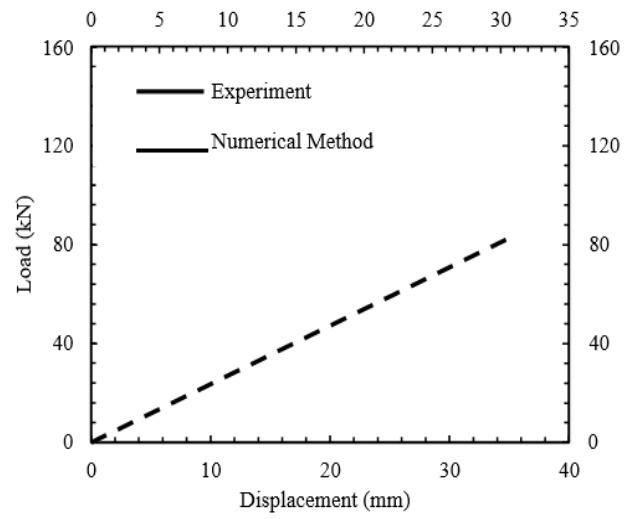

Figure 16. Comparison of the load-displacement curve between the experimental and numerical result.

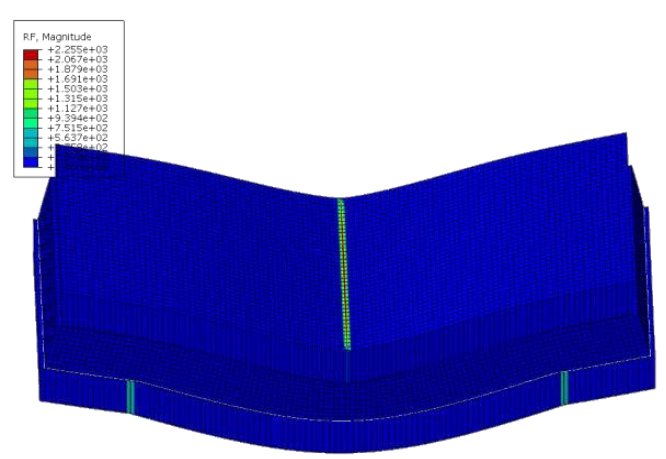

Figure 17. Reaction force contour of sandwich bending analysis.

initiated as the flexural crack appears at the mid-span. As the load continues, more flexural cracks were formed, and the core fracture become more evident. At this stage, the load capacity of the sandwich drops. A simple numerical model using 3D non-linear finite element analysis was carried out and was able to predict the response of the specimen under flexural loading. However, more sophisticated constitutive law for the core material which incorporate the fracture energy should be developed in the future.

\section{REFERENCES}

H. Kilic and R. Haj-Ali, "Progressive damage and nonlinear analysis of pultruded composite structures," Composites, vol. 34 , no. 3, pp. 235-250, 2003.

[2] S. Herman, J. Wellnitz, S. Jahn, and S. Leonhardt, "Structural Health Monitoring for Carbon Fiber Resin Composite Car Body Structures," Sustain. Automot. Technol., pp. 75-96, 2013.

[3] K Abdullah, "Application of Sandwich Plate System Made from Core Shellfish Waste on the Ship Deck," J. Ilm. Teknol. Marit., vol. 12, no. 2, pp. 53-60, 2019.

[4] SH Sujiatanti, "Finite Element Analysis of Ship Deck Sandwich Panel," Trans Tech Publ., vol. 874, pp. 134-139, 2018.

[5] A. Zubaydi, A. Budipriyanto, and S. H. Sujiatanti, "Studi Numerik dan Eksperimental Identifikasi dan Monitoring Kerusakan Struktur Kapal Berbahan Sandwich Panel," Surabaya, 2018.

[6] K. Ramakrishnan and P. Kumar, "Application of Sandwich Plate System for Ship Structures," IOSR J. Mech. Civ. Eng., pp. 83-90, 2016.

[7] N. Momcilovic and M. Motok, "Estimation of Ship Lightweight Reduction by Means of application of Sandwich Plate System," FME Trans., vol. 37, no. 3, pp. 123-128, 2009.

[8] U. E. and B. A., "Prelimenary Study of Sandwich Panel Application In Ship Construction: Combination of Plywood and Polyurethane Material," in Seminar Nasional Teori dan Aplikasi Teknologi Kelautan, 2015.

[9] P. Kujala and K. Alan, "Steel Sandwich Panels in Marine 
Applications," Brodograndja, vol. 56, no. 4, pp. 305-314, 2005

[10] E. Utomo, A. Zubaydi, and P. Pratisna, "Study of Core Material Sandwich Panel In Ship Construction," in The 2nd International Seminar on Science and Technology, 2017.

[11] S. Zubaydi, "Development of Sandwich Core Material for Deck Structure," Int. J. Civ. Eng. Technol., vol. 9, no. 11, pp. 2551-2560, 2018.

[12] K. Abdullah, A. Zubaydi, and A. Budipriyanto, "Development Of Sandwich Panel With Core From Clamshell Powder For Ship Structure," in SENTA 2017 - International Conference on Marine Technology, 2017.

[13] A. Mula, A. Zubaydi, and A. Budipriyanto, "Properties of Sandwich Panel Core From Eggshell Powder For Ship Structure," in SENTA 2017 - International Conference on Marine Technology, 2017.

[14] Yudiono, A. Budipriyanto, and A. Zubaydi, "Tests On
Sandwich Plate Core Materials With Rice Husk Filler For Ship Deck Structure," in SENTA 2017 - International Conference on Marine Technology, 2017.

[15] M. S. Purwoko, A. Budipriyanto, and A. Zubaydi, "Study on Wood Sawdust for Sandwich Core Material of Ship Structure," in SENTA 2017 - International Conference on Marine Technology, 2017.

[16] ASTM International, "ASTM C 393 - 00 Standard Test Method for Flexural Properties of Sandwich Constructions,' 2000.

[17] L. Register, "Provisional Rules for The Application of Sandwich Panel Construction to Ship Structure," United Kingdom, 2015.

[18] W. Iswidodo, "Multiple Damages Identification of Sandwich Panel Material on Ship Structure Using Vibration Response," Surabaya, 2017. 